\title{
Development of Nanolubricant Using Aloe Vera Plant to Enhance the Thermal Performance of a Domestic Refrigeration System
}

\author{
Sunday A. Afolalu ${ }^{1}$, Omolayo M. Ikumapayi ${ }^{1 *}$, Adebayo T. Ogundipe ${ }^{2}$, Olabisi O. Yusuf ${ }^{3}$, Olamilekan R. Oloyede ${ }^{1}$ \\ ${ }^{1}$ Department of Mechanical and Mechatronics Engineering, Afe Babalola University, Ado Ekiti 360101, Nigeria \\ ${ }^{2}$ Directorate of Information Communication Technology, Afe Babalola University, Ado Ekiti 360101, Nigeria \\ ${ }^{3}$ Department of Microbiology, Obafemi Awolowo University, Ile-Ife 220282, Nigeria
}

Corresponding Author Email: Ikumapayi.omolayo@abuad.edu.ng

https://doi.org/10.18280/ijht.390626

Received: 24 September 2021

Accepted: 10 November 2021

\section{Keywords:}

green chemistry, lubricating oil, nanoparticle, nanotechnology, refrigeration

\begin{abstract}
Power consumption is a significant issue in developing countries, and the refrigerator is one of the largest consumers of electricity. Nanoparticles functioning as additives to refrigerants or lubricating oils help reduce compressor work and reduce the power consumption of refrigerators. In this study, zinc oxide nanoparticles were developed using Aloe Vera leaves and dispersed in mineral oil to reduce the compressor work and increase the performance of a domestic vapour compression refrigeration system. After the successful synthesis of the nanoparticles, spectroscopical investigations using EDS revealed the nanoparticles to have $73.31 \%$ zinc, $20.19 \%$ oxygen and $6.40 \%$ carbon indicating a significant phase of zinc oxide. Microstructural studies on the nanoparticles revealed an average nanoparticle size of $4.68 \mathrm{~nm}$ within the nanometric range. The nanoparticles were dispersed in mineral oil in concentrations of $0.5 \mathrm{~g} / 250 \mathrm{ml}, 0.75 \mathrm{~g} / 250$ $\mathrm{ml}, 1 \mathrm{~g} / 250 \mathrm{ml}, 1.25 \mathrm{~g} / 250 \mathrm{ml}$ and $1.5 \mathrm{~g} / 250 \mathrm{ml}$ of the oil and fed into the compressor to check the effect of each concentration on the performance of the refrigerator. The control sample contained pure mineral oil. The system was monitored for 225 minutes per sample, and coefficient of performance was determined. The results indicate an increase in COP by $14-15 \%$ from $0.4 \mathrm{wt} \%$ and $0.6 \mathrm{wt} \%$ respectively.
\end{abstract}

\section{INTRODUCTION}

Power supply is a major problem in developing countries, and the refrigerator is one of the largest components that require adequate power supply for effective and efficient operations. To increase its performance and reduce the consumption of electricity, it is therefore, very important to introduce nanoparticles into the systems. The field of nanotechnology is a widely spread and researched area, such that more scientists are delving into finding solutions to medical research, electronics, physics, and many others with nanoparticles, nanotubes, and other nano-sized bodies [1]. Nanoparticles functioning as additives to refrigerants or lubricating oils help reduce compressor work and reduce the power consumption of refrigerators. A refrigerant is a fluid substance basically in the liquid or gaseous state, which brings out the refrigeration effect. Thermodynamically, refrigeration is a "means of transferring heat from a low-temperature reservoir to a high-temperature reservoir". According to Kumar et al. [2], refrigeration is the process of cooling products and substances from a higher temperature within an enclosed space to a low temperature. Thus, in refrigerator manufacture, the inclusion of a lubricant means formulating unique blends compatible with the refrigerant, refrigerator, and the environment [3]. However, as invented by Paul Anastas, green chemistry involves using safe substances and eliminating harmful chemicals in synthesising new compounds, which is a sub-method of the biological synthesis method. The biological method developed in the last few years has received more attention regarding its lower toxicity, safer and faster preparation in the synthesis of nanoparticles than the other two methods. In this method, protein or peptides from algae or microscopic organisms (viruses, bacteria, and fungi) and different non-harmful plant sources from the environment are used as reducing agents in the synthesis of mostly metallic nanoparticles and is found to have a higher success rate in nanoparticles synthesis [4].

Aloe Vera plant (Aloe Barbadensis Miller), belonging to the family of Asphodelaceae, is a common shrub that grows worldwide, especially in Africa. The plant has been successfully used as a reducing agent for silver, gold and zinc oxide nanoparticles. The resulting zinc oxide nanoparticles have been majorly employed in different areas of medicine. Thus, the specific objectives of this study are: (1) develop and synthesise nano lubricant using the aloe vera plant; (2) evaluate the performance of the developed nano lubricant; (3) carry out performance evaluation in a domestic refrigerator; and (4) validate results by comparing them to the performance evaluation of a control (mineral oil) [5]. Aloe vera resembles a cactus because it is fleshy, has thorns all along periphery of its leaf tissue, is wax-coated, and holds a huge amount of water. Aloe vera contains over 75 bioactive components, such asn minerals, fat-soluble vitamins, phenolic compound, simple and complex polysaccharides, organic acids, enzymes, in addition to 99 percent to 99.5 percent water. Aloe vera is a 400 -species lily belonging to the Aloe barbadensis group. Aloe vera is well recognised for its therapeutic capabilities, and it has traditionally been used to treat inflammation and soreness 
[6]. Zinc oxide is one of the most commonly used metal oxide nanoparticles and its applications vary from the medical and scientific word (as in bio-medics) and engineering. The problem, however, as with other nanoparticles is the synthesis. The formerly used methods were toxic and the disposal of the particles was far more harmful. Recently, a group of nanoscientists created the biological synthesis method using plants, bacteria and other biological organisms to synthesize $\mathrm{ZnO}$. Among the plants used is Aloe Barbadensis Miller. However, the applications of the Aloe juice-capped Zinc oxide has only been used for the production of biomedical drugs [6] and as water filters [7].

Zinc oxide is an inorganic substance that comes in the form of a white powder that is water insoluble. It is commonly utilised as an addition in a wide range of materials and applications. $\mathrm{ZnO}$ is a white powder when pure, although it is found in nature as the rare mineral zincite. Amphoteric oxides, such as zinc oxide, are a type of oxide. In water, it is practically insoluble, yet it dissolves with most acids. The features of $\mathrm{ZnO}$ include binding ability, high refractive index, antimicrobial capabilities, high thermal conductivity, as well as UV protection. Zinc Oxide is a unique composition with unrivalled photoelectrochemical attributes. It is known for being a nontoxic inorganic metal with unmatched electrical and optical properties, as well as being multidimensional with several potential uses [8]. ZnO has a wide range of applications in superconducting materials and electromechanical attributes, including piezoelectric devices, biosensor, nature conservation, photodetectors, pharmaceuticals, and perfumery, and even fabric treatment technology. However, $\mathrm{ZnO}$ possesses photo electrocatalytic qualities and is used in the food sector, as well as the agricultural sector, for its antifungal benefits. By altering the size and shape, all of the qualities and applications can be altered. Furthermore, due to its antioxidant, antibacterial, and anti-inflammatory properties, $\mathrm{ZnO}$ Nanoparticles have a wide spectrum of uses in biological and medical fields, including therapeutic nanomedicine and the beauty products [9].

\section{MATERIALS AND METHODS}

Aloe Vera stalks, zinc nitrate Hexahydrate crystals $\left[\mathrm{Zn}\left(\mathrm{NO}_{3}\right)_{2} .6 \mathrm{H}_{2} \mathrm{O}\right]$, distilled water, R-134a refrigerant, mineral oil as a control are the major materials used in this research.

\subsection{Preparation of aloe vera extract}

Aloe Vera leaves were sourced from a local market in Ota, Ogun State, Nigeria. First, the leaves were washed with distilled water to remove adhering dust and dirt particles. Afterwards, the skins were scraped off and chopped into fine pieces. The chopped pieces were then blended in about $100 \mathrm{ml}$ of deionised water. The resulting solution was cooled to room temperature before it was filtered. The mixture was then stored in different bottles at low temperatures in a refrigerator for preservation [10].

\subsection{Green synthesis of zinc oxide}

To achieve an environmentally safe method of producing nano-zinc oxide, aloe vera juice (extract) was employed as the reducing agent in the biological synthesis as depicted in Figure 1. Approximately $297 \mathrm{~g}$ of $\mathrm{Zn}\left(\mathrm{NO}_{3}\right)_{2} \cdot 6 \mathrm{H}_{2} \mathrm{O}$ [zinc nitrate hexahydrate] crystals were weighed into a beaker followed by a solution of $500 \mathrm{ml}$ distilled water. The mixture was stirred until complete dissolution. After that, $350 \mathrm{~g}$ of the aloe vera extract was added into the mixture resulting in an aloe vera extract-Zn mixture maintained at $0.25 \mathrm{M}$. This was repeated to gain enough nanofluid so that the resulting nanoparticles would be adequate for the experiment. The reaction mixture was then agitated with the aid of a magnetic stirrer for 5 hours at $150^{\circ} \mathrm{C}$. Finally, the miscible liquid obtained was centrifuged in $10 \mathrm{~mL}$ centrifuge tubes at $4000 \mathrm{rpm}$ for $15 \mathrm{mins}$. Centrifugation was done to separate the denser liquid or gel from the diluted solution [11].

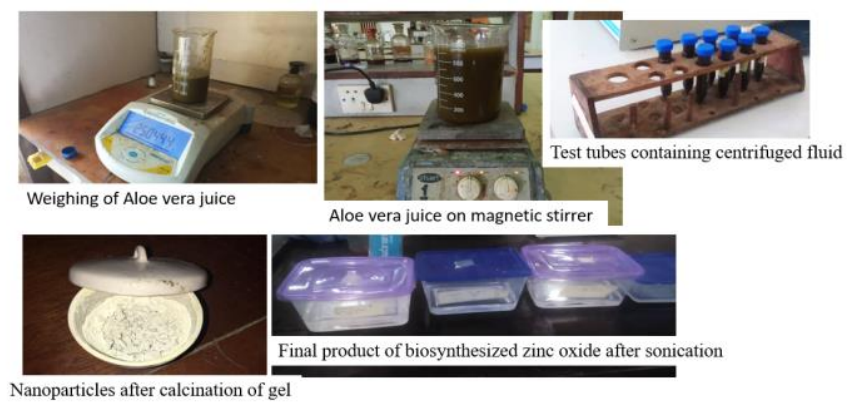

Figure 1. Biosysnthes of $\mathrm{ZnO}$ from Aloe vera juice

The reaction equations:

$$
\mathrm{Zn}\left(\mathrm{NO}_{3}\right)_{2} \cdot 6 \mathrm{H}_{2} \mathrm{O}+\mathrm{H}_{2} \mathrm{O} \rightarrow \mathrm{Zn}\left(\mathrm{NO}_{3}\right)_{2}+7 \mathrm{H}_{2} \mathrm{O}
$$

Then,

$$
\begin{aligned}
\mathrm{Zn}\left(\mathrm{NO}_{3}\right)_{2}+7 \mathrm{H}_{2} \mathrm{O} & + \text { Aloe vera juice } \\
& \rightarrow \text { Aloe capped Zinc solution }
\end{aligned}
$$

$$
\begin{aligned}
& \text { Aloe capped Zinc solution }--- \\
& \quad \rightarrow \text { Conc. ALE } \\
& - \text { ZnO gelatinous precipitate } \\
& \text { Centrifuging }
\end{aligned}
$$

\subsection{Preparation of zinc oxide nanoparticles}

With deionized water of $500 \mathrm{ml}$ by volume, aloe vera gel broth extracted at a concentration of $95 \%$ were synthesized. Following that, about $297 \mathrm{~g}$ of hydrated zinc nitrate was mixed in the aloe extract solution for 120 minutes with steady magnetic stirring and then allowed to settle for 12 hours and suspension (gelatinous precipitate obtained from centrifuging was stored in a cool, dry place) and was also thermally treated (calcined) for 2 hours, at $750^{\circ} \mathrm{C}$ in a muffle furnace. For the preparation of the nanoparticles, ceramic crucibles were sanitised to prevent contamination. Then, the gelatinous precipitate was scraped out using spatulas from the centrifuge tubes into the crucibles. There was further heat-treatment to allow for homogeneity of the nanoparticles and to remove any foreign materials (impurities) that may be present after calcination, and this was done at $200^{\circ} \mathrm{C}$ for 24 hours and was monitored [12].

$$
\begin{gathered}
\text { ALE - ZnO gelatinous ppt. }+\mathrm{O}_{2}--- \\
\rightarrow \mathrm{CO}_{2}+\mathrm{H}_{2} \mathrm{O}_{(\mathrm{g})}+\mathrm{ALE} \\
-\mathrm{ZnO} \text { nanoparticles } \\
\text { Combustion }
\end{gathered}
$$




\subsection{Preparation of nanolubricant fluid}

Colloidal preparations of nanoparticles in the base fluid are known as nanofluids. The size of these nanoparticles ranges from 1 to 100 nanometers. The form of nanoparticle employed has a big impact on the base fluid's desired characteristics. $\mathrm{ZnO}$ nanoparticles were employed as an addition in the mineral oil-based lubricant. The nanofluid is more than a liquid-solid blend of mineral oil and zinc oxide. It must be stable, long-lasting suspension with little agglomeration. This allows for long-term use in the compressor. The degree of diffusion and permanence of nanoparticles within the base fluid is one of the most influential factors on the properties of nanofluids. When nanoparticle distribution in the base fluid is inefficient, agglomeration and precipitation of nanoparticles can occur, causing macroparticles to form, which can impair the frictional surface and block the lubricant vents. In this study, five samples of the nanolubricant were prepared by ultrasonic agitation. $0.5 \mathrm{~g}, 0.75 \mathrm{~g}, 1.0 \mathrm{~g}, 1.25 \mathrm{~g}$ and $1.5 \mathrm{~g}(0.2$, $0.3,0.4,0.5$ and $0.6 \mathrm{wt} \%$ ) of the $\mathrm{ZnO}$ nanoparticles were each dissolved in $250 \mathrm{ml}$ of mineral oil before ultrasonic agitation for $3 \mathrm{~h}$ per sample.

\subsection{Experimental application of nanolubricant in domestic refrigerator}

The refrigerator was setup with thermocouples and pressure gauges. The setup is shown in Figure 2. Then the compressor was charged with the R134a refrigerant and one concentration of the nanolubricant sample per time. The refrigerator was monitored for 225 minutes per sample and parameters noted were the cabinet temperature, suction temperature and pressure and discharge temperature and pressure. These were used to determine the pull-down time, variation in compressor discharge temperature, net refrigerating effect and coefficient of performance [13]

$$
\begin{aligned}
& \text { Net refrigerating effect }(\mathrm{NRE})=h_{2}-h_{1} \text { in } \frac{\mathrm{J}}{\mathrm{kg}} \\
& \text { Cooling capacity }=\dot{\mathrm{m}}\left(h_{1}-h_{3}\right) \\
& \text { Coefficient of Performance }=\frac{\dot{\mathrm{m}}\left(h_{1}-h_{3}\right)}{\dot{\mathrm{m}}\left(h_{2}-h_{1}\right)}
\end{aligned}
$$

but $h=C_{p} T$

$$
\therefore \text { Coefficient of Performance }=\frac{C_{p} T_{1}-C_{p} T_{3}}{C_{p} T_{2}-C_{p} T_{1}}
$$

where, $\dot{\mathrm{m}}=$ mass flow rate of refrigerant, $h_{2}, T_{2}=$ superheated vapour enthalpy and temperature in $\mathrm{J} / \mathrm{kg}$ and ${ }^{\circ} \mathrm{C}$ respectively; $h_{l}, T_{l}=$ saturated vapour enthalpy and temperature in $\mathrm{J} / \mathrm{kg}$ and ${ }^{\circ} \mathrm{C}$ respectively; $h_{3}=$ saturated liquid enthalpy in $\mathrm{J} / \mathrm{kg}$; $C_{p}=$ specific heat capacity of refrigerant at constant pressure in $\mathrm{kcal} / \mathrm{kg}^{\circ} \mathrm{C}$; Parameters were gotten using R134a thermodynamic tables.

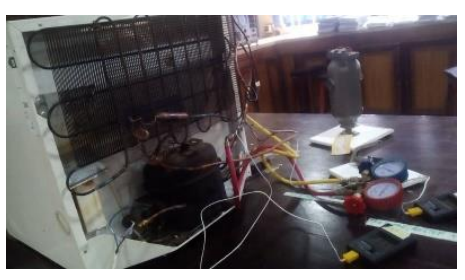

Figure 2. Refrigerator setup

\subsection{Characterisation of ale/ zinc oxide nanoparticles}

JSM-7600F Schottky Field Emission Scanning Electron Microscope (SEM) was used to determine the developed nanoparticles' surface topography and structural analysis. Furthermore, Electro-Dispersive X-ray Spectroscopy (EDS) was carried out to indicate the composition of the synthesised $\mathrm{ZnO}$ nanoparticles and aloe vera in determining the suitability for this investigation.

\section{RESULTS AND DISCUSSIONS}

\subsection{Coefficient of performance}

The coefficient of performance is a major measure of determining the performance of the refrigerator. A higher COP means less power consumption, greater efficiency. Mathematically, it is expressed as shown in Eq. (9) [14-16].

$$
\mathrm{COP}=\frac{\mathrm{h}_{1}-\mathrm{h}_{3}}{\mathrm{~h}_{2}-\mathrm{h}_{1}}
$$

Table 1 shows the obtained variation in coefficient of performance for all the samples and the control over time.

Table 1. Variation in coefficient of performance (COP)

\begin{tabular}{ccccccc}
\hline \multicolumn{7}{c}{ Coefficient of Performance (COP) } \\
\hline CONTROL & S1 & S2 & S3 & S4 & S5 & Time (min) \\
\hline 10.404 & 11.967 & 12.588 & 11.181 & 19.6 & 13.752 & 15 \\
8.192 & 9.548 & 5.917 & 7.486 & 13.85 & 11.464 & 30 \\
6.624 & 8.718 & 5.96 & 6.102 & 11.362 & 10.455 & 45 \\
6.457 & 7.592 & 5.142 & 5.82 & 9.135 & 9.457 & 60 \\
6.19 & 7.768 & 5 & 5.426 & 7.398 & 7.118 & 75 \\
5.461 & 6.552 & 4.465 & 5.078 & 6.477 & 7.116 & 90 \\
5.142 & 6.324 & 4.026 & 5.08 & 6.158 & 7.024 & 105 \\
5.369 & 5.77 & 4.026 & 4.938 & 6.318 & 6.786 & 120 \\
5.61 & 5.643 & 4.141 & 4.938 & 5.877 & 6.414 & 135 \\
5.467 & 5.541 & 4.17 & 4.938 & 5.731 & 6.184 & 150 \\
5.122 & 4.972 & 4.141 & 5.08 & 5.495 & 5.782 & 165 \\
4.825 & 4.932 & 3.997 & 4.938 & 5.436 & 5.659 & 180 \\
4.627 & 4.738 & 4.105 & 4.899 & 5.436 & 5.54 & 195 \\
4.575 & 4.844 & 4.2 & 4.899 & 5.436 & 5.54 & 210 \\
4.724 & 4.598 & 3.973 & 4.899 & 5.43 & 5.369 & 225 \\
\hline
\end{tabular}


Evaluating the Figure 3, Sample $5(0.6 \mathrm{wt} \%)$ indicates a $13.66 \%-71.84 \%$ increase while Sample $3(0.4 \mathrm{wt} \%)$ indicates a $14.9 \%-71.5 \%$ increase in COP as compared to the values of the control. Samples 1, 2 and 4 indicate lower COP values than that of the control sample.

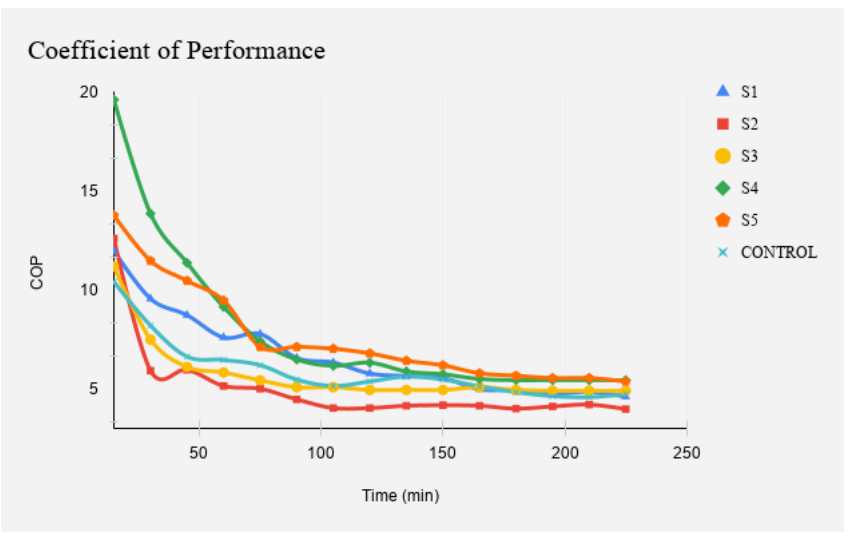

Figure 3. Variation of COP

\subsection{Scanning electron microscope (SEM)}

The particles were characterised with field emission scanning electron microscope, and analysis indicated a mean average particle area of $13.94 \mathrm{~nm}^{2}$, the minimum value being $1.003 \mathrm{~nm}^{2}$ and the maximum value being $282.66 \mathrm{~nm}^{2}$ while the mean of the nanoparticle length is $4.86 \mathrm{~nm}$ with a range of 1.26 $\mathrm{nm}$ to $36.69 \mathrm{~nm}$. The micrographs shown in Figure 4 were taken at a magnification of 16000,20000 , and 18000 with working distances of $12 \mathrm{~mm}, 15 \mathrm{~mm}$, and $18 \mathrm{~mm}$ respectively, and with an acceleration voltage of $20 \mathrm{kV}$ resulting to $20 \mu \mathrm{m}$, $50 \mu \mathrm{m}$ and $100 \mu \mathrm{m}$ respectively as shown in Figure 4 (a, b, c). The micrographs also indicated clusters of near-spherical particles, which are normal compared to other research works.

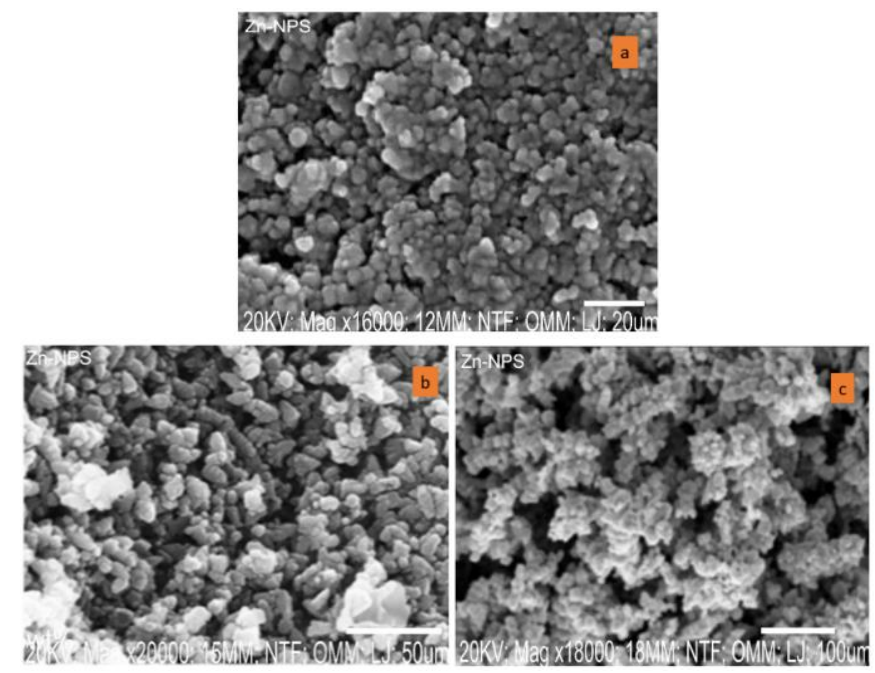

Figure 4. SEM micrographs of developed nanolubricant powder (a) $20 \mu \mathrm{m}$ (b) $50 \mu \mathrm{m}$ (c) $100 \mu \mathrm{m}$

\subsection{Electro-dispersive X-ray spectroscopy (EDS)}

EDS was carried out to determine the compositional analysis of the aloe vera and the resulting nanoparticles. The EDS micrograph in Figure 5 shows that $\mathrm{ZnO}$ nanoparticles contain $73.31 \%$ Zinc, $20.29 \%$ Oxygen and $6.40 \%$ Carbon concentrations. Thus, the primary phase being $\mathrm{ZnO}$ which indicate that the nanoparticles are indeed $\mathrm{ZnO}$ nanoparticles.
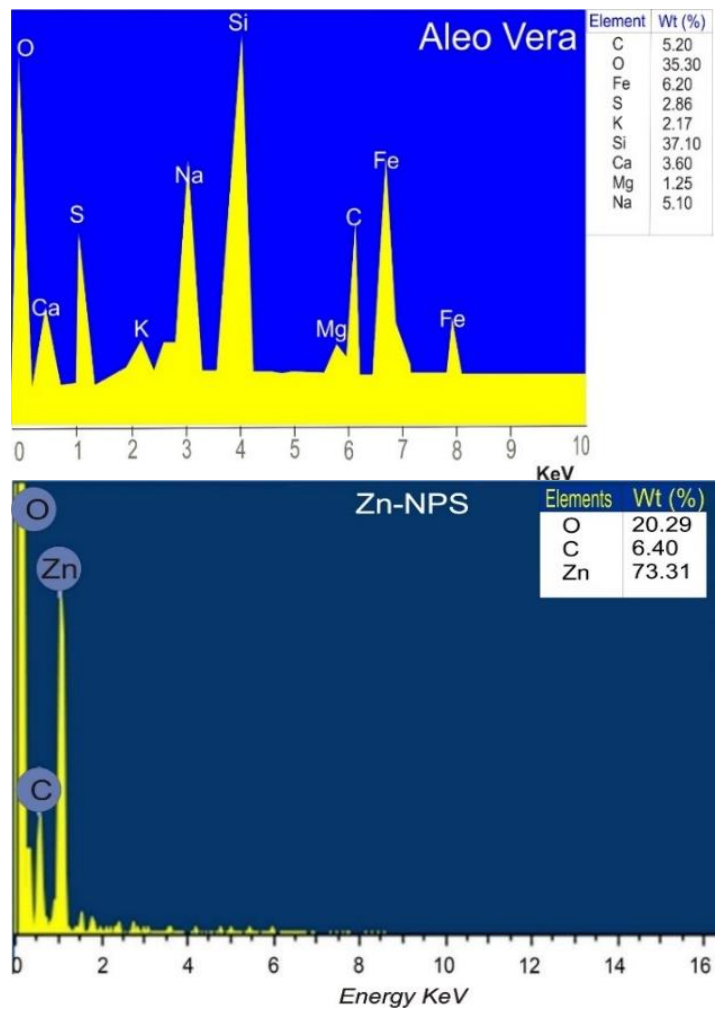

Figure 5. EDS micrograph for (a) aloe vera (b) developed nanoparticles

\section{CONCLUSIONS}

This research successfully utilised the aloe vera plant (Aloe Barbadensis Miller) as a reducing agent to synthesise $\mathrm{ZnO}$ nanoparticles from zinc nitrate hexahydrate crystals and used in a compressor lubricating oil to investigate its effect on the refrigeration performance. The results show an increase in COP of almost $15 \%$ in the $0.4 \mathrm{wt} \%$ concentrations of the nanoparticle and almost $14 \%$ in the $0.6 \mathrm{wt} \%$ concentration sample, indicating the best effect on the refrigeration, as compared to the control sample after 225 minutes of operation. Therefore, green synthesis in refrigeration shows a very promising application in developing cost-effective and safe nanoparticles for refrigeration from the obtained results.

\section{ACKNOWLEDGMENT}

We acknowledge the financial support offered by Afe Babalola University, Ado Ekiti in the actualisation of this research work for publication.

\section{REFERENCES}

[1] Elegbede, J.A., Lateef, A. (2019). Green nanotechnology in Nigeria: The research landscape, challenges and prospects. Annals of Science and Technology, 4(2): 6-38. https://doi.org/10.2478/ast-2019-0008

[2] Kumar, G.S., Deepika, P., Kumar, M.N., Kumar, B.M., Kumar, K.N. (2018). Performance analysis of VCR's 
using nanorefrigerants. International Research Journal of Engineering and Technology, 5(3): 3869-3872.

[3] Ajayi, O.O., Ukasoanya, D.E., Ogbonnaya, M., et al. (2019). Investigation of the effect of $\mathrm{R} 134 \mathrm{a} / \mathrm{Al}_{2} \mathrm{O}_{3}-$ nanofluid on the performance of a domestic vapour compression refrigeration system. Procedia Manufacturing, 35: 112-117. https://doi.org/10.1016/j.promfg.2019.05.012

[4] Duan, H., Wang, D., Li, Y. (2015). Green chemistry for nanoparticle synthesis. Chemical Society Reviews, 44(16):

5778-5792. https://doi.org/10.1039/C4CS00363B

[5] Akev, N., Can, A., Sütlüpınar, N., et al. (2015). Twenty years of research on Aloe vera. İstanbul Üniversitesi Eczacılık Fakültesi Dergisi, 45(2): 191-215.

[6] Anju, T.R., Parvathy, S., Veettil, M.V., Rosemary, J., Ansalna, T.H., Shahzabanu, M.M., Devika, S. (2021). Green synthesis of silver nanoparticles from Aloe vera leaf extract and its antimicrobial activity. Materials Today: Proceedings, 43: 3956-3960. https://doi.org/10.1016/j.matpr.2021.02.665

[7] Fardsadegh, B., Jafarizadeh-Malmiri, H. (2019). Aloe vera leaf extract mediated green synthesis of selenium nanoparticles and assessment of their in vitro antimicrobial activity against spoilage fungi and pathogenic bacteria strains. Green Processing and Synthesis, 8(1): 399-407. https://doi.org/10.1515/gps2019-0007

[8] Medina-Cruz, D., Vernet-Crua, A., Mostafavi, E., et al. (2021). Aloe vera-mediated Te nanostructures: Highly potent antibacterial agents and moderated anticancer $\begin{array}{lll}\text { effects. } & \text { Nanomaterials, } & 11(2) \text { : }\end{array}$ https://doi.org/10.3390/nano11020514

[9] Rasli, N.I., Basri, H., Harun, Z. (2020). Zinc oxide from aloe vera extract: Two-level factorial screening of biosynthesis parameters. Heliyon, 6(1): e03156. https://doi.org/10.1016/j.heliyon.2020.e03156

[10] Ali, K., Dwivedi, S., Azam, A., Saquib, Q., Al-Said, M.S., Alkhedhairy, A.A., Musarrat, J. (2016). Aloe vera extract functionalized zinc oxide nanoparticles as nanoantibiotics against multi-drug resistant clinical bacterial isolates. Journal of Colloid and Interface Science, 472: 145-156. https://doi.org/10.1016/j.jcis.2016.03.021

[11] Sangeetha, G., Rajeshwari, S., Venckatesh, R. (2011). Green synthesis of zinc oxide nanoparticles by aloe barbadensis miller leaf extract: Structure and optical properties. Materials Research Bulletin, 46(12): 25602566. https://doi.org/10.1016/j.materresbull.2011.07.046

[12] Adelekan, D.S., Ohunakin, O.S., Babarinde, T.O., Odunfa, M.K., Leramo, R.O., Oyedepo, S.O., Badejo, D.C. (2017). Experimental performance of LPG refrigerant charges with varied concentration of $\mathrm{TiO}_{2}$ nano-lubricants in a domestic refrigerator. Case Studies in Thermal Engineering, 9: 55-61. https://doi.org/10.1016/j.csite.2016.12.002

[13] Ajayi, O.O., Useh, O.O., Banjo, S.O., et al. (2018). Investigation of the heat transfer effect of $\mathrm{Ni} / \mathrm{R} 134 \mathrm{a}$ nanorefrigerant in a mobile hybrid powered vapour compression refrigerator. In IOP Conference Series: Materials Science and Engineering, 391(1): 012001. https://doi.org/10.1088/1757-899X/391/1/012001

[14] Ajayi, O.O., Aba-Onukaogu, C.C., Salawu, E.Y., et al. (2019). Effect of biomaterial (Citrullus Lanatus Peels) nanolubricant on the thermal performance and energy consumption of r600a in refrigeration system. In Energy Technology 2019, pp. 91-102. https://doi.org/10.1007/978-3-030-06209-5_9

[15] Raghavalu, K.V., Rasu, N.G. (2018). Review on applications of nanoFluids used in vapour compression refrigeration system for cop enhancement. In IOP Conference Series: Materials Science and Engineering, 330(1): $\quad 012112$. https://doi.org/10.1088/1757$899 X / 330 / 1 / 012112$

[16] Zamare, D., Vutukuru, S.S., Babu, R. (2016). Biosynthesis of nanoparticles from agro-waste: A sustainable approach. International Journal of Engineering Applied Sciences and Technology, 1(12): 85-92. 